\title{
Optimum Design of Multi-Function Robot Arm Gripper for Varying Shape Green Product
}

\author{
Zol Bahri Razali ${ }^{1, *}$, Mohammad Haniff Othman ${ }^{1}$ and Mohd Hisam Daud ${ }^{1}$ \\ ${ }^{1}$ Robotics and Automation Technology, Faculty of Engineering Technology, Universiti Malaysia \\ Perlis, 02100 Padang Besar, Perlis, Malaysia
}

\begin{abstract}
The project focuses on thorough experimentally studies of the optimum design of Multi-function Robot Arm Gripper for varying shape green product. The purpose of this project is to design a few of robot arm gripper for multi-functionally grip a green product with varying shape. The main character of the gripper is that it can automated adjust its finger to suit with the shape of the product. An optimum design of multi-function robot arm gripper is verified through experimental study. The expected result is a series of analytical results on the proposal of gripper design and material that will be selected for the gripper. The analysis of the gripper design proposal by using ANSYS and CATIA software is described in detail in this paper.
\end{abstract}

\section{Introduction}

In a robotic system, the one of the most important part is the robotic gripper. The unit between the robot and the work piece is the gripper. That is the reason in an automated framework, the choice of the gripper is extremely imperative [1]. There are a lot variety kinds of grippers, the most common types of grippers are jaw type, vacuum and magnetic grippers.

In the industries, the type of mechanical gripper that most commonly used is jaw type, it have a fingers that move parallel. Depending on the jaw design, two-jaw gripper consists with two gripping fingers that apply pressure internally or externally on the object [2]. The gripper hold the object by uses two or more fingers that move toward each other.

In this era, a lot of the gripper has been desiged or created. The gripper is often designed according to the needs and desires of users. In the market, the users difficult to search the good material and design for the gripper robotic arm for varying shape product. A survey was conducted for studied about fundamental and experimentally studies of the behavior and mechanical properties for optimum design for multi-function robot arm gripper for varying shape product.

\footnotetext{
*Corresponding author : zolbahri@unimap.edu.my
} 


\section{Literature Review}

Gripper. In a mechanical framework, the one amongst the most vital part is the automated gripper. The unit between the robot and the work piece is the gripper. That is why in a robotic system, the selection of the gripper is very important. There are a lot variety kinds of grippers, the most common types of grippers are jaw type, vacuum and magnetic grippers. It also can be categorized into three main groups, single surface gripper, clamping grippers and flexible grippers [1].

Jaw type gripper. Jaw type grippers are related to clamping gripers. The design is so simple, so it is not surprising the gripper clamp is one of the cheapest on the market. In the jaw type grippers, the simplest type is two-jaw gripper. Two jaw gripper types are most widely used in industry because it requires a lower cost to make it. This is because, the gripper is the easiest type to designed. Two jaw gripper includes with two gripping finger pressure imposed externally or internally on an object depends on the jaw design. It could be used for objects that are large and small. Mechanics for jaw-finger movements can include linkage, cam, pinion, actuators, pneumatic and hydraulic cylinder. When the object is too complex and difficult to grasping by two jaw gripper, three jaw gripper is the best choice for more complex objects. The three jaw grippers (Figure 1) using pressure as two jaw grippers but consist of three grasping fingers. The three jaw grippers are more expensive and therefore complicated than two-jaw grippers [3].

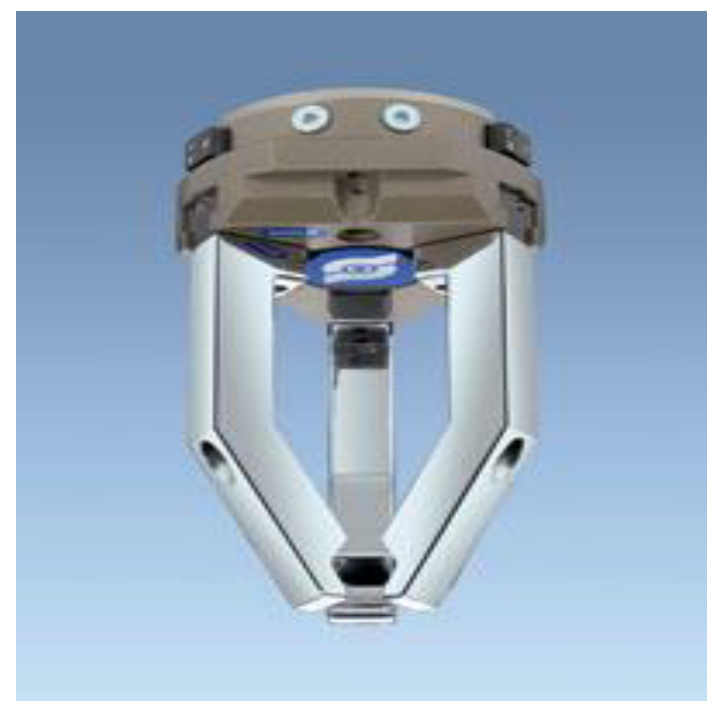

Fig. 1. Type of jaw gripper.

Magnetic gripper. Magnetic gripper is in the main group of single surface gripper, when the grippers have only one surface of component that available. These types are suitable for pick up the product that has a light and heavy weight and flat component when it difficult to controlled by the others main group of grippers. Magnetic grippers are divided into two types; electromagnet and permanent magnet. Magnetic gripper only suitable for grasping, and pick up types of ferrous materials. For permanent Magnets, the materials will be used that's from the nature of the magnetic. Permanent magnets require a mechanism to release the gripped object [4]. In addition to permanent magnet, the magnetic field cans also be generated from electricity. It will be created by a wire wounded into a coil. The point when power through the wires, an attractive field will be produced and will be lost when there is no electricity. Mostly electromagnetic are often used to take various types of metal 
and steel waste. The electromagnetic grippers can pick and release the ferrous object in a few second and easy to control [5]. Other benefits with electromagnetic grippers are that they can resist high forces [4].

Vacuum gripper. Vacuum grippers are also in the main group of single surface grippers. Vacuum gripper consists of a suction cup as pick up devices. The suction cup is created out of rubber. The tubes are associated through suction cups with under pressure devices for picking up item with air is sucked and releasing item with air is pumped out into the suction cups. The suction cups are mostly made by polyurethane or rubber that can stand by temperatures between -50 and $200^{\circ} \mathrm{C}$. There are different types of suction cups, depth suction cup, universal suction cups, suction cups with bellow and flat suction cups with bars as shown in Figure 3 [6].

Universal suction cup is always applied to the surface is slightly curved and flat surface. In the market, the one of the cheapest suction cups is universal suction cups but at the type of suction cups, there have a several disadvantages. Under the pressure is too high, the vacuum gripper should use larger suction cup. For flat or flexible items that require assistance when lifted, flat suction cup with a bar is the best choice. These kinds of suction cup provides a small opening under load and keep the area under the pressure acting, this reduces wear on the flat with a suction cup bar, this makes the movement becomes faster and more secure. For suction cups with bellow, mostly it is used for curved surface. It is suitable for the separation of an object, grip smaller items and requires shorter movement. The depth suction cups are suitable for lifted over and edge, for curve and irregular surface. Vacuum gripper has a problem to a product that has a rough surface and a product that has holes in its surface. It will be difficult when the product is porous because the suction cups cannot sucked the surface [6].

Flexible grippers are new in the market. These main groups are difficult to handle and design. It consists with a few linkages on each finger and that have a two or more finger to pick up the product. These grippers are like a human hand. It is called multi finger gripper. This type of gripper can pick up products that have a complex shape because the gripper can control individually of the linkage in the fingers.

\section{Methods and Materials}

Propose of Design. In this project, some designs will be proposed for a different concept, developed and analysed by using ANSYS and CATIA software. As the proposal, three designs in different concept will be proposed, based on an observation and detail study about the application and characteristice of grippers. Figure 2, 3 and 4 show the proposed design with its green design concept.

Design 1: Human-hand concept. This is a robotic peripheral that is designed for industrial applications. Its design makes it a unique robotic end of arm tool to pick, place and handle a large range and volume of parts of varying sizes and shapes. This gripper constructed using stainless steel. In the grippers industries, stainless steel is suitable for lift the heavy weight product. The design is most complicated, but it suitable for pick a heavy weight product. The advantage for this design is it can pick any shape of product like a human hand. This design only has a three finger for pick and lifts the product. Figure 2 shows the reason why this design has only a three finger. 


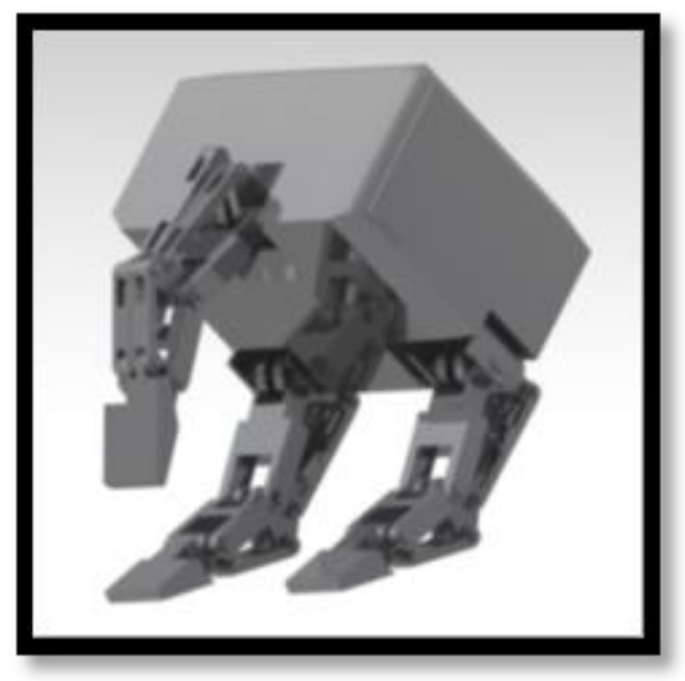

Fig. 2. Design 1- Human-hand concept.

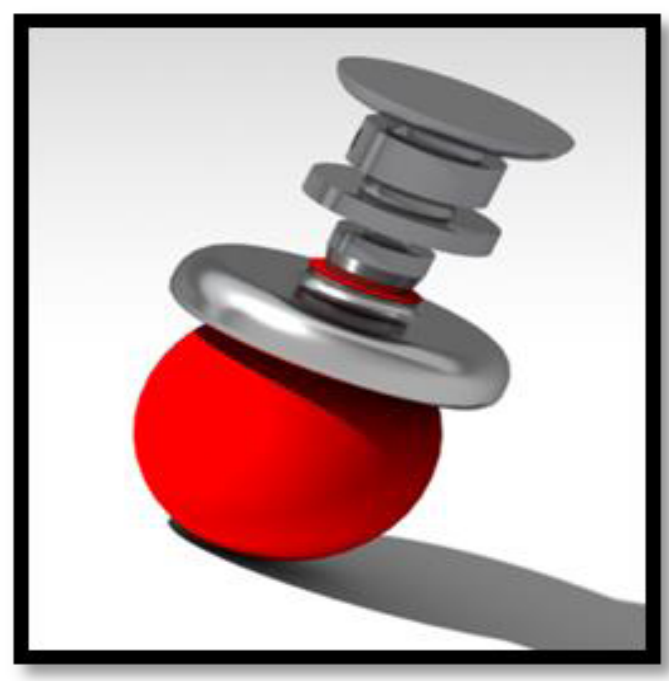

Fig. 3. Design 2- Ball sucker concept.

Design 2: Ball-sucker concept. Gripping and holding of objects are key tasks for robotic manipulators. The development of universal grippers able to pick up unfamiliar objects of widely varying shape and surface properties remains, however, challenging. Most current designs are based on the multi-fingered hand, but this approach introduces hardware and software complexities. These include large numbers of controllable joints, the need for force sensing if objects are to be handled securely without crushing them, and the computational overhead to decide how much stress each finger should apply and where. Here we demonstrate a completely different approach to a universal gripper. Individual fingers are replaced by a single mass of granular material that, when pressed onto a target object, flows around it and conforms to its shape. Upon application of a vacuum the granular material contracts and hardens quickly to pinch and hold the object without requiring sensory feedback. This advance opens up new possibilities for the design of simple, yet highly adaptive systems that excel at fast gripping of complex objects. Tasks 
that appear simple to humans, such as picking up objects of varying shapes, can be vexingly complicated for robots. Secure gripping not only requires contacting an object, but also preventing potential slip while the object is moved. Slip can be prevented either by friction from contact pressure or by exploiting geometric constraints, for example by placing fingers around protrusions or into the opening provided by the handle of a cup. For reliable robotic gripping, the standard design approach is based on a hand with two or more fingers, and typically involves a combination of visual feedback and force sensing at the fingertips. The advantage of the design is can pick and place varying shape product through the object has a complex shape.

Design 3: Inflatable-pockets concept. In this design, following an extensive review and discussion on different gripper types and design issues in the first section, a flexible gripper design based on the use of compliant materials and internal pressure of inflatable rubber pockets. This type of grippers conforms to the shape of an object by means of elastic gripping elements and pressurization with active degrees of freedom. The advantage of this design is can lift any shape of product without damaged the surface of the product.

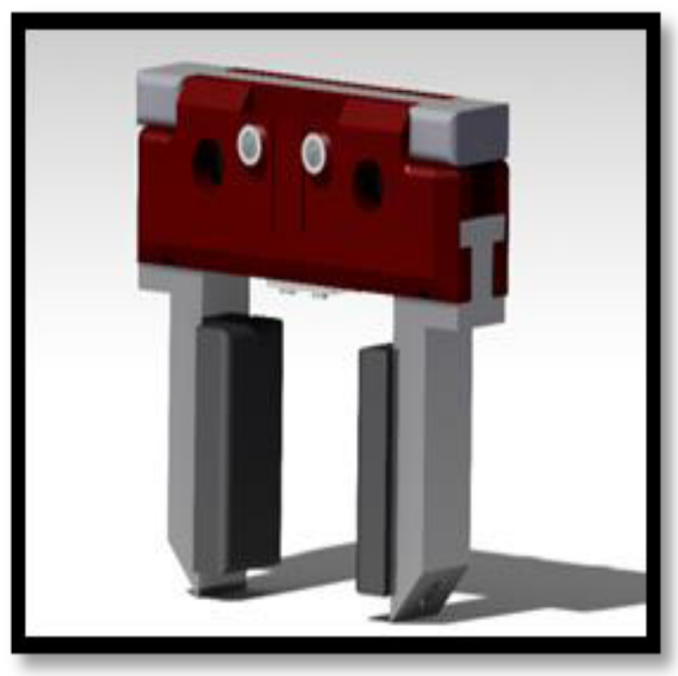

Fig. 4. Design 3 - Inflatable pockets concept.

\section{Comparison of design}

Analytic Hierarchy Process. Complete criteria comparison matrix [7] using 1-9 ratings described in Table 1. The table shows the comparison between operation, maintenance, durability and design that which most important for this design.

Table 1. The comparison matrix between characteristic (matric $[\mathrm{C}]$ ).

\begin{tabular}{|c|c|c|c|c|c|}
\hline Criteria & Operation & Maintenance & Durability & Design & Total \\
\hline Operation & 1.00 & 5.00 & 3.00 & 5.00 & 14.00 \\
\hline Maintenance & 0.20 & 1.00 & 9.00 & 7.00 & 17.20 \\
\hline Durability & 0.333333333 & 0.111111111 & 1.00 & 3.00 & 4.444444444 \\
\hline Design & 0.20 & 0.142857143 & 0.333333333 & 1.00 & 1.676190476 \\
\hline TOTAL & 1.733333333 & 6.253968254 & 13.33333333 & 16.00 & \\
\hline
\end{tabular}


Table 2 shows the result of comparison matrix between characteristic. The rating at table 4.2 will be multiply with total of rating. The consistency of characteristic can be measure in this process.

Table 3 shows the comparison of characteristic of three design of gripper for varying shape product. This table helps to give a score for the comparative advantage of each design. All score will be referring in this table.

Table 2. The consistency measure of characteristic.

\begin{tabular}{|c|c|c|c|c|c|c|c|}
\hline Criteria & 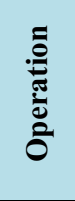 & 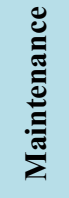 & 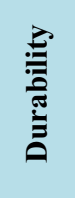 & 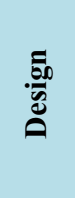 & 吾 & $\begin{array}{l}\stackrel{8}{\pi} \\
\frac{\pi}{0} \\
\frac{\pi}{4}\end{array}$ & 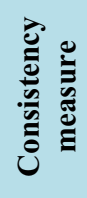 \\
\hline Operation & 0.58 & 0.80 & 0.23 & 0.31 & 1.91 & 0.48 & 5.96 \\
\hline Maintenance & 0.12 & 0.16 & 0.68 & 0.44 & 1.39 & 0.35 & 5.48 \\
\hline Durability & 0.19 & 0.02 & 0.08 & 0.19 & 0.47 & 0.12 & 4.11 \\
\hline Design & 0.12 & 0.02 & 0.03 & 0.06 & 0.23 & 0.06 & 4.27 \\
\hline TOTAL & 1.00 & 1.00 & 1.00 & 1.00 & & 1.00 & 19.82 \\
\hline
\end{tabular}

Table 3. The design characteristic of gripper for varying shape product.

\begin{tabular}{|c|c|c|c|c|}
\hline Characteristic & Parameter & Design 1 & Design 2 & Design 3 \\
\hline Operation & rating & very good & $\begin{array}{c}\text { very } \\
\text { good }\end{array}$ & good \\
\hline Maintenance & month & 6 & 3 & 3 \\
\hline Durability & material & stainless steel & rubber & $\begin{array}{c}\text { stainless steel and } \\
\text { rubber }\end{array}$ \\
\hline Design & shape & $\begin{array}{c}\text { most } \\
\text { complicated }\end{array}$ & simplest & not complicated \\
\hline
\end{tabular}

Table 4 shows the comparison of operation for each design. The result show design 1 and 2 get a same score. If it is able to get a little bit score, it shows that it is a good design.

Table 4. Comparison between operation of design 1, 2 and 3.

\begin{tabular}{|c|c|c|c|c|}
\hline Operation & Rating & Design 1 & Design 2 & Design 3 \\
\hline Design 1 & $\begin{array}{c}\text { very } \\
\text { good }\end{array}$ & 1.00 & 1.00 & 3.00 \\
\hline Design 2 & $\begin{array}{c}\text { very } \\
\text { good }\end{array}$ & 1.00 & 1.00 & 3.00 \\
\hline Design 3 & good & 0.333333333 & 0.3333333333 & 1.00 \\
\hline sum & & 2.333333333 & 2.333333333 & 7.00 \\
\hline
\end{tabular}

Table 5 is used to get the average score for critical measure of rating for operation in each design after get the data from Table 4.

Table 6 shows the comparison of maintenance for each design. The result show design 2 and 3 get a same score. But this result show the design 1 is most good from another design. Design 1 gets a highest score because this design takes a long time to be maintenance. It shows that this design is not easily damaged. 
Table 5. Critical measure of rating between design 1, 2 and 3.

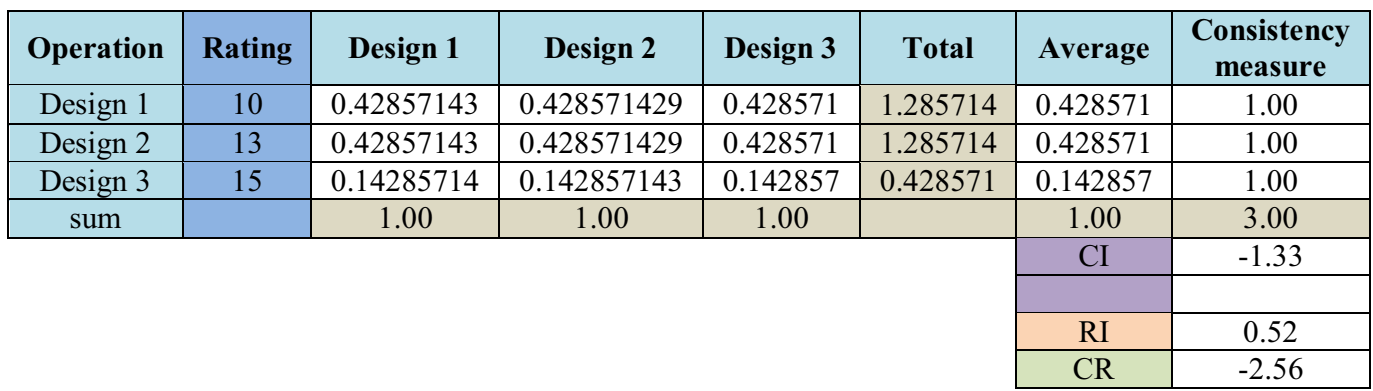

Table 6. Comparison between maintenance of design 1, 2 and 3.

\begin{tabular}{|c|c|c|c|c|}
\hline Maintenance & Month & Design 1 & Design 2 & Design 3 \\
\hline Design 1 & 6 & 1.00 & 2.00 & 2.00 \\
\hline Design 2 & 3 & 0.50 & 1.00 & 1.00 \\
\hline Design 3 & 3 & 0.50 & 1.00 & 1.00 \\
\hline sum & & 2.00 & 4.00 & 4.00 \\
\hline
\end{tabular}

Table 7 is used to get the average score for critical measure of rating for maintenance in each design after get the data from table 6 . This table shows design 1 get the highest score from another design.

Table 8 shows the comparison of maintenance for each design. The result show the design 1 is most good from another design. Design 1 gets highest score because it only used a stainless steel. Stainless steel has a strong durability than a rubber.

Table 7. Critical measure of maintenance between design 1, 2 and 3.

\begin{tabular}{|c|c|c|c|c|c|c|c|}
\hline maintenance & month & Design 1 & Design 2 & Design 3 & Total & average & $\begin{array}{c}\text { consistency } \\
\text { measure }\end{array}$ \\
\hline Design 1 & 4 & 0.50 & 0.50 & 0.50 & 1.50 & 0.50 & 1.00 \\
\hline Design 2 & 3 & 0.25 & 0.25 & 0.25 & 0.75 & 0.25 & 1.00 \\
\hline Design 3 & 3 & 0.25 & 0.25 & 0.25 & 0.75 & 0.25 & 1.00 \\
\hline \multirow[t]{4}{*}{ sum } & & 1.00 & 1.00 & 1.00 & & 1 & 3.00 \\
\hline & & & & & & $\mathrm{CI}$ & -1.33 \\
\hline & & & & & & RI & 0.52 \\
\hline & & & & & & $\mathrm{CR}$ & -2.56 \\
\hline
\end{tabular}


Table 8. Comparison between durability of design 1, 2 and 3 .

\begin{tabular}{|c|c|c|c|c|}
\hline durability & material & Design 1 & Design 2 & Design 3 \\
\hline Design 1 & Stainless Steel & 1.00 & 5.00 & 3.00 \\
\hline Design 2 & Rubber & 0.20 & 1.00 & 0.60 \\
\hline Design 3 & Stainless Steel and Rubber & 0.333333333 & 1.666666667 & 1.00 \\
\hline sum & & 1.533333333 & 7.666666667 & 4.60 \\
\hline
\end{tabular}

Table 9 shows the comparison of design (shape) for each design. The result shows the design 2 is most good from another design. Design 2 gets highest score because this design is simplest to build compare with each design.

Table 9. Comparison between design and design 1, 2 and 3.

\begin{tabular}{|c|c|c|c|c|}
\hline Design & Shape & Design 1 & Design 2 & Design 3 \\
\hline $\begin{array}{c}\text { Design } \\
1\end{array}$ & $\begin{array}{c}\text { most } \\
\text { complicated }\end{array}$ & 1.00 & 0.111111111 & 0.333333333 \\
\hline $\begin{array}{c}\text { Design } \\
2\end{array}$ & simplest & 9.000000009 & 1.00 & 1.00 \\
\hline $\begin{array}{c}\text { Design } \\
3\end{array}$ & $\begin{array}{c}\text { not } \\
\text { complicated }\end{array}$ & 3.000000003 & 1.00 & 1.00 \\
\hline sum & & 13.00000001 & 2.111111111 & 2.333333333 \\
\hline
\end{tabular}

\section{Finite Elemen Analysis.}

It is seen from Figure 5, the moments about joints are;

$$
\begin{array}{ll}
M 1=F^{*}(L 1+L 2+L 3) & M 1=70 F \\
M 2=F^{*}(L 2+L 3) & M 2=41 F \\
M 3=F^{*}(L 3) & M 3=20 F
\end{array}
$$

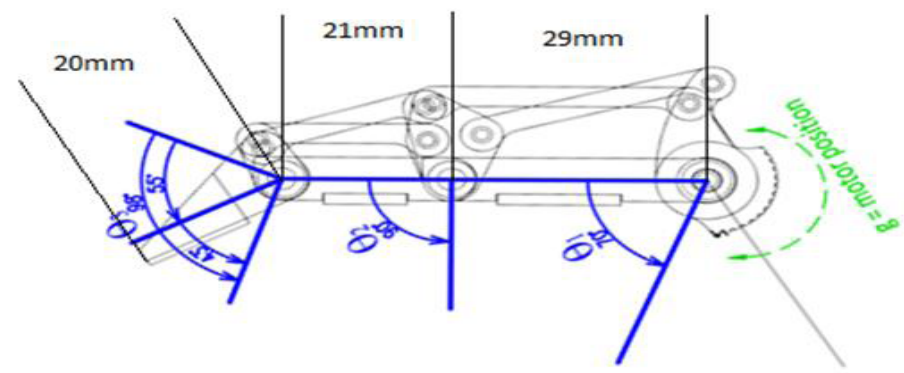

Fig. 5. Schematic Representation of Finger. 
The critical moment that creates the tension is M1. After definition of $\mathrm{M}$ as reaction moment on joint 1 then it is written as;

$$
M 1=M
$$

Where

(3)

$$
M=T^{*} \mathrm{rp}
$$

Here, $\mathrm{T}$ is the tension force on rope and $\mathrm{rp}$ is the radius of pulley at joint 1. From Eq.2 and Eq.3,

$$
\begin{gathered}
70 F=T^{*} 6 \\
T=11.667 F
\end{gathered}
$$

After determination of tension force on rope the torque value of the actuator is calculated from;

$$
T \mathrm{a}=T * \mathrm{ra}
$$

Where ra is radius of actuator gear and $\mathrm{ra}=10.5 \mathrm{~mm}$

$$
\begin{aligned}
& T \mathrm{a}=11.667 F^{*} 10.5 T \mathrm{a}=123 F[\text { N.mm }] \\
& T \mathrm{a}=0.123 F[\text { N.m }]
\end{aligned}
$$

For 6 bar pressure, torque value for actuator is 2 [N.m]. Then; using this value and equation 4.6b, maximum gripping force for the tip point of the finger is calculated as;

$$
\frac{1}{123 F[\mathrm{~N} . \mathrm{mm}]} \times 2=0.01626 \mathrm{kN} ; \quad F=16.26[\mathrm{~N}]
$$

By taking the coefficient of friction as 0.5 [8] (covering material), Maximum carrying capacity of one finger can be calculated as;

$$
\mathrm{m}=\mathrm{F} * \mu / \mathrm{g} \quad \mathrm{m}=16.26 * 0.5 / 9.81 \quad \mathrm{~m}=0.8287[\mathrm{~kg}]
$$

From the result calculated in Eq.8, the gripping capacity of the hand for three fingers and palm can be calculated as;

$$
\mathrm{mG}=3 * \mathrm{~m} \mathrm{mG}=2.4862[\mathrm{~kg}]
$$

Finally, it is necessary to define an equation for torque-pressure relation for the actuator of the gripper in order to determine finger force for an open loop gripping force control [8]. The actuators used in the gripper are rotary vane type pneumatic actuators. So, torque value of the actuator is linearly proportional to applied pressure and defined as;

$$
\text { Torque Factor } \mathrm{x} \text { Pressure }=\text { Torque Output }
$$


Using Eq.10, torque factor for actuator is found as;

$$
\text { Torque Factor }=2[\mathrm{~N} . \mathrm{m}] / 600000[\mathrm{~N} / \mathrm{m} 2]=0.334 \times 10^{-5}[\mathrm{~m}]
$$

Then, torque-pressure relation for the actuator is defined as;

$$
T \mathrm{a}=0.334 \times 10^{-5} P
$$

In this equation, unit of Ta is [N.m] and $\mathrm{P}$ is [N/m2]. Using Eq. $6 \mathrm{~b}$ and Eq.12, the relationship between pressure and the gripping force is obtained as;

$$
F=1.662 \times 10^{-5} P
$$

Here, unit of $F$ is $[\mathrm{N}]$ and $\mathrm{P}$ is $[\mathrm{N} / \mathrm{m} 2]$. Eq.13 is valid for pressure ranges between 2 and 8 bars which is the operating range of the actuator.

\section{Analysis of Design}

From the force Analysis for fingers result calculated in Eq. 8, Maximum carrying capacity of one finger is $0.8287 \mathrm{~kg}$. The gripping capacity of the hand for three fingers and palm is $2.4862 \mathrm{~kg}$. In the theoretical, the maximum carrying capacity for this design is $2.4862 \mathrm{~kg}$ by length of the fingers. The result will be used to analysis the design. $2.4862 \mathrm{~kg}$ is equal to $24.4 \mathrm{~N}$. For this analysis, $30 \mathrm{~N}$ force will be applied to finger to get the data of total deformation, equivalent elastic strain and equivalent stress. In the creation of the gripper, the most commonly used materials are aluminum and stainless steel. In the industries of gripper, aluminum is mostly used for lift light objects and stainless steel is used to lift extreme weight objects. For this model, the parts of gripper will be constructed from stainless steel to make a gripper able to stand in the long time.

Deformation in continuum mechanics is the transformation of a body from a reference configuration to a current configuration. Figure 6 shows the analysis of total deformation of finger. The maximum deformation is $3.3215 \mathrm{~mm}$. 


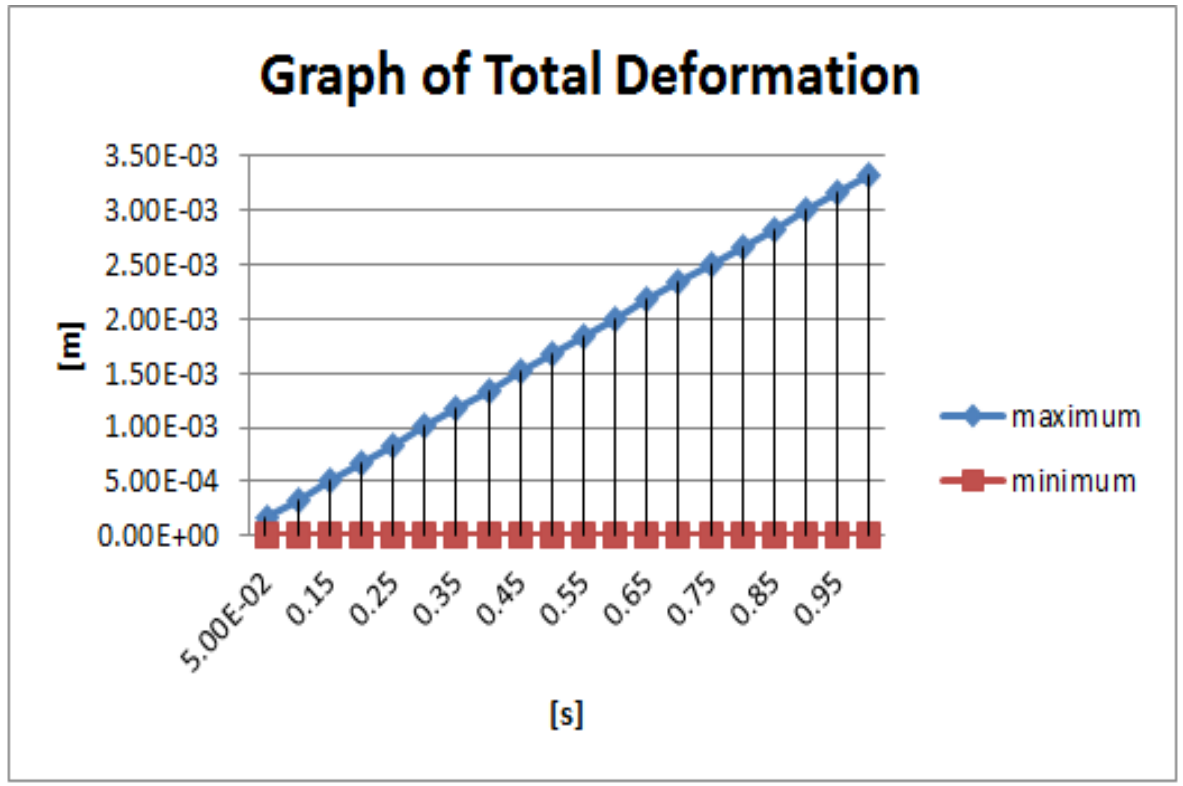

Fig.6. Graft of total deformation.

Figure 7 shows the result of equivalent elastic strain. Equivalent elastic strain is a form of strain in which the distorted body returns to its original shape and size when the deforming force is removed. The maximum strain is $0.044578 \mathrm{~m} / \mathrm{m}$.

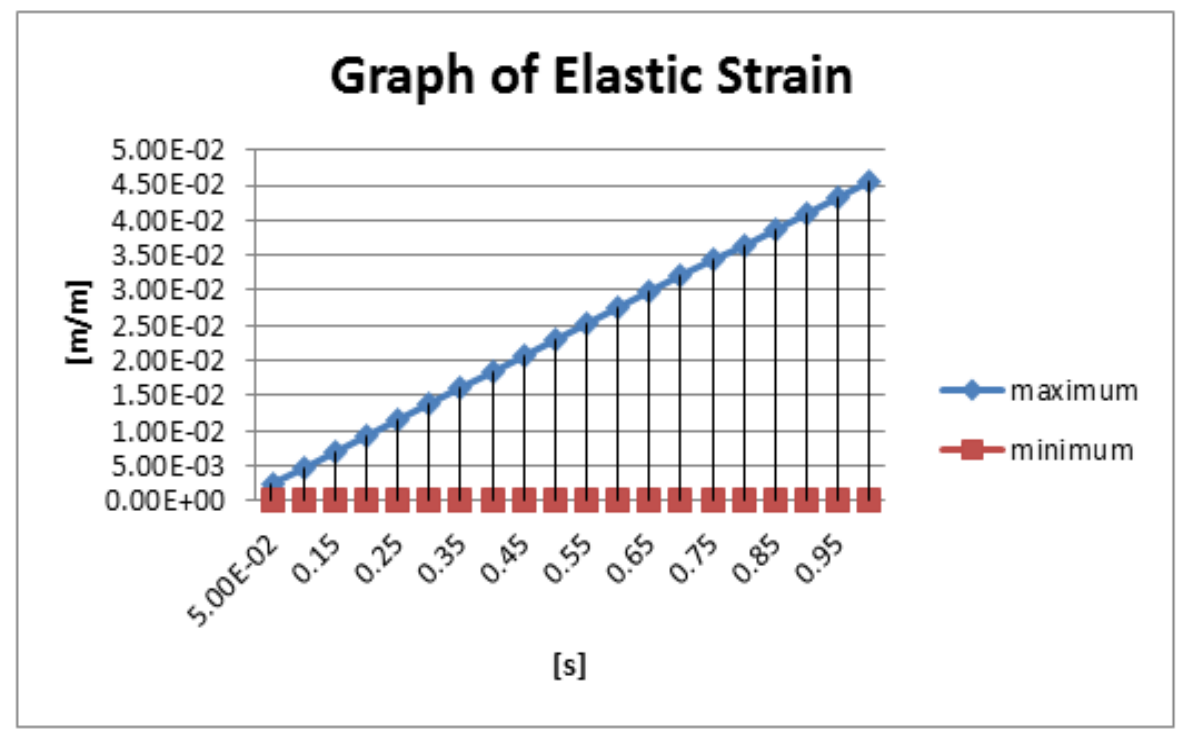

Fig. 7. Graft of elastic strain. 


\section{Conclusion}

To design a gripper tool for an industrial robot has been very instructive. In this paper, detail method of designing an optimum robotic gripper is described and implemented. The gripper has been shown to be able to handle a variety of shapes and sizes. The objective for determining, selecting and designing the proposed green robot gripper is achieved. As the main objective is to optimally design multifunction robot arm gripper for varying shape of green product, is done by using CATIA software. Other than that, the comparison of the gripper design to choose the best design also completed by using the Analytic Hierarchy Process (AHP). For the analysis of FEA (finite element analysis), the result was get by using ANSYS software. The result shows that the selected design can stand by the pressure that was applied. For the conclusion, the optimum design of this gripper can be highlighted so that it can be marketed in the industries.

This work was financially supported by the Universiti Malaysia Perlis Seed Money (9014-00034).

\section{References}

1. Z.B. Razali, N.A. Mat Nawi, Automated Segregating Device for Reuse and Recycle Waste (Lambert, Chicago, 2013)

2. L.U. Odhner, L.P. Jentoft, M.R. Claffee, N. Corson, Y. Tenzer, R.R. Ma, M. Buehler, R. Kohout,R.D. Howe, A.M. Dollar, Int. J. Rob. Res., 33, 736 (2014)

3. D.T. Pham, E. Tacgin, Int. J. Mach. Tool Manu., 32, 349 (1992)

4. G.J. Monkman, S. Hesse, R. Steinmann, H. Schunk, Robot Grippers, (WILLEY-VCH, Germany, 2007)

5. P.V.P. Reddy, V.V.N. Satya Suresh, Int. J. Mech. Eng. Robot. Res., 2, 255 (2013)

6. Z.B. Razali, G.B. Lee. High-End Technology for Effective Glass Manufacturing Industry (Lambert, Chicago, 2013)

7. T.L. Saaty, L.G. Vargas, Models, Methods, Concepts \& Applications of the Analytic Hierarchy Process (Springer, New York, 2012)

8. S.H. Cho, S.D. Eppinger, ASME 2001 Design Engineering Technical Conferences and Computers and Information in Engineering Conference (2001) 